MODIFICAÇÃO DA PERLITA EXPANDIDA COM ORTOFENANTROLINA PARA A FORMAÇÃO DE SÍTIOS ATIVOS

PARA CORANTES ÁCIDOS: PREPARAÇÃO E CARACTERIZAÇÃO

\title{
MODIFICATION OF EXPANDED PERLITE WITH ORTHOPHENANTHROLINE FOR FORMATION OF ACTIVE SITES FOR ACID DYES: PREPARATION AND CHARACTERIZATION
}

\author{
ALMEIDA, Janiele Mayara Ferreira $\mathrm{de}^{1^{*}} ;$ SILVA, Isabel do Nascimento ${ }^{2}$; DAMASCENO \\ JUNIOR, Elmar'; FERNANDES, Nedja Suely ${ }^{3}$ \\ 1,2,3,4 Universidade Federal do Rio Grande do Norte, Instituto de Química, Caixa postal 1524 - Campus \\ Universitário Lagoa Nova, CEP 59078-970 | Natal - RN, Brasil \\ * Corresponding author \\ e-mail: Janielequimicaufrn@gmail.com
}

Received 25 October 2017; received in revised form 19 March 2018; accepted 19 March 2018

\section{RESUMO}

A perlita expandida (aluminosilicato naturalmente ácido) foi modificada com ortofenantrolina (base de Lewis). O material foi caracterizado por TG/DTA, DRX e IV. A curva termogravimétrica da perlita expandida modificada apresentou menor estabilidade térmica devido à ortofenantrolina e mostrou 13,6\% da total perda de massa. No entanto, a perlita expandida pura apresentou apenas $2,3 \%$ da perda de massa. A curva DTA mostrou evento endotérmico característico da presença de ortofenantrolina. Para a análise DRX é visualizada, a presença de reflexões no difratograma relativo ao material modificado de picos de cristalina de ortofenantrolina, uma vez que nenhuma perlita de modificação é um material amorfo. A banda em relação à vibração de absorção do grupo Si-O aparece em números de onda inferiores ao do material não modificado. Assim, houve uma interação entre os grupos $\mathrm{OH}$ de silanóis de grupos de perlita com pares de elétrons não compartilhados de átomos de nitrogênio e ligações $C=C$ (também ricas em elétrons) na estrutura química da ortofenantrolina como resultado de uma ligação de hidrogênio entre esses grupos. Assim, a perlita foi modificada através da interação de seus sítios ácidos $(\mathrm{Si}-\mathrm{OH})$ com sítios básicos de Lewis de ortofenantrolina.

Palavras-chave: Aluminossilicato, perlita expandida, ortofenantrolina, corantes ácidos, adsorção.

\section{ABSTRACT}

The expanded perlite (aluminosilicate naturally acid) has been modified with orthophenanthroline (Lewis base). The material was characterized by TG/DTA, XRD and IR. The thermogravimetric curve of the modified expanded perlite presented a lower thermal stability due to the orthophenanthroline and showed $13,6 \%$ of mass loss total. However, pure expanded perlite presented only $2,3 \%$ of the mass loss. The DTA curve showed endothermic event characteristic of the presence of orthophenanthroline. For XRD analysis is visualized, the presence of reflections in the diffractogram relating to the modified material of orthophenanthroline peaks of crystallinity since no modification perlite is an amorphous material. The band regarding absorption vibration of Si-O group appears at lower wavenumbers than in the unmodified material. So there was an interaction between the $\mathrm{OH}$ groups of silanols of perlite groups with unshared electron pairs of nitrogen atoms and $\mathrm{C}=\mathrm{C}$ bonds (also rich in electrons) in the chemical structure of orthophenanthroline as a result of a hydrogen bond between these groups. thus perlite was modified through the interaction of its acid sites (Si-OH) with Lewis basic sites of orthophenanthroline.

Keywords: aluminosilicate, expanded perlite, orthophenanthroline, acids dyes, adsorption. 


\section{INTRODUCTION}

The modification of aluminosilicate aims to control its physical and chemical properties so that the material can be used for the purpose you want. The search for materials to improve the adsorptive capacity of the aluminosilicate has been extensively studied for many fields of research in this area. Perlite is a volcanic rock with a glassy structure and a composition being rhyolitic family member of amorphous silica and an aluminosilicate according to the literature featuring $71-75 \%$ of $\mathrm{SiO}_{2}$ in its composition. The perlite can be found in expanded form as it is produced by heating in a temperature range of $760-1100{ }^{\circ} \mathrm{C}$ where its original volume expands 4 to 20 times increasing the size of its pores (CHASSAPIS et al, 2010; DOGAN et al, 2000; ALKAN e DOGAN, 1998; SILBER et al, 2010).

Perlite has hydroxyl groups in its structure. In the field of research, the expanded perlite is widely used as a support in catalysis and adsorption processes because of their chemical composition and structural chemical properties. The expanded perlite is material with the potentially acidic surface, and so interacts better with the basic dyes in the adsorption processes. The adsorptive capacity of perlite is attributed to the presence of silanol groups (SiOH) (DOGAN, ALKAN E ÇAKIR, 1997).

Barka et al, (2011) an efficient dye removal process for aqueous solutions is adsorption. Several works in the literature highlight the adsorption efficiency for the treatment of water contaminated with dyes, using several adsorbent materials: activated carbon, sand, polymer, zeolites and clays (AGUIAR et al, 2002; VARLIKLI et al, 2009; DOTTO et al, 2011; HERNANDEZ -MONTOYA 2013).

In the dyes removal of aquatic environments, the expanded perlite without modification proved to be very effective when used as an adsorbent in adsorption processes to substances with basic characters, such as cationic dyes and metals (ACEMIOGLU, 2005; ROULIA e VASSILIADIS, 2005; GHASSABZADEH et al., 2010). However, the need to remove acidic substances, such as anionic dyes, due to their chemical characteristics, the expanded perlite is not efficient, thus requiring a chemical modification that provides active sites to receive these types of molecules. This study is significant since in adsorption processes necessary adsorbent material is inexpensive, abundant and not harmful to the environment, which requirement perlite plenamente follows. The expanded perlite is an excellent material in the environmental remediation, particularly as an adsorbent in adsorption processes.

Expanded perlite modification processes are still poorly described in the literature, but aiming to improve its physical and chemical properties for use in different applications, this procedure was adopted by some authors.

The expanded perlite was modified by adsorption with humic substances (are found in organic soils, river banks, and oceans, originated from the microbial metabolism of plants and animals existing there. They are amorphous biopolymers and multifunctional high in carbohydrates, aromatic rings with phenolic substituent carboxyl and methoxyl). This work showed that the perlite has a high affinity for this type of substance (ROULIA et al, 2006).

Manganese oxide for modification of perlite, getting what they called Mn-EP (expanded perlite modified with manganese). This material (EP-Mn) was developed by the authors for the application as an adsorbent antimony (III) ions, what proved to be quite efficient in this pollutant removal process compared to perlite without change via adsorption process (SARI, SAHINOGLU e TUZEN, 2012).

With this approach, orthophenanthroline, a Lewis base, was used to modify the surface of the expanded perlite to interact with the silanol groups, to promote basic active sites on the surface of the aluminosilicate, so that it can receive the acid type dye molecules.

\section{EXPERIMENTAL METHODS}

\section{1 cleaning of expanded perlite}

The expanded perlite used in this work is from Argentina and provided by Schumacher Petrochemicals, Company of Rio Grande do Sul, Brazil.

Initially, the expanded perlite was washed to remove any impurities or foreign bodies that may have been incorporated into the material during storage or handling. Weighed $10 \mathrm{~g}$ of expanded perlite and mixed with $200 \mathrm{~mL}$ of distilled water, leaving the mixture under constant agitation and at room temperature for 24 hours. After this time, filtered the mixture in a 
quantitative filter paper ( $8 \mu \mathrm{m}$ of pore) using a vacuum pump, and thereafter dried expanded perlite in an oven with forced air circulation for 4 hours at $110^{\circ} \mathrm{C}$.

After the cleaning, the expanded perlite was sifted in a sieve of 100 mesh, and the material was stored in a clean, dry container.

\subsubsection{Modification of expanded perlite with orthophenanthroline}

The orthophenanthroline was used, aiming to modify the surface of the expanded perlite so that the adsorbent material can get the acid molecules.

For the modification procedure of expanded perlite, initially prepared $250 \mathrm{~mL}$ of solution orthophenanthroline (o-phenanthroline monohydrate, $\mathrm{C}_{12} \mathrm{H}_{8} \mathrm{~N}_{2} \cdot \mathrm{H}_{2} \mathrm{O}$, of 198,24 molar mass g.mol ${ }^{-1}$, InLab mark) concentration 0.1 mol. $\mathrm{L}^{-1}$ by diluting in $25 \mathrm{~mL}$ of ethyl alcohol and completing the volume with distilled water in a flask volume of $250 \mathrm{~mL}$. Subsequently weighed approximately $6,0 \mathrm{~g}$ of expanded perlite washed and dried, and mixed in a beaker to orthophenanthroline solution of $0,1 \mathrm{~mol} / \mathrm{L}$ with 6,0 $\mathrm{g}$ of expanded perlite, the mixture leaving into contact for $4 \mathrm{~h}$ under constant stirring of $150 \mathrm{rpm}$ at room temperature $\left(25,0 \pm 1,0{ }^{\circ} \mathrm{C}\right)$. Finally the procedure, perlite filtered through a quantitative filter paper by vacuum filtration, washing the perlite with water to remove the excess of orthophenanthroline solution, observing the $\mathrm{pH}$ after each wash the perlite with distilled water. This washing was done by observing an approximately constant $\mathrm{pH}$, as close as possible to neutrality. Dry the adsorbent material in an oven with forced air circulation at $60^{\circ} \mathrm{C}$ for $4 \mathrm{~h}$.

\subsection{Characterization of materials}

\subsubsection{Thermal analysis (TG/DTA)}

The materials (Expanded Perlite, the orthophenanthroline and the expanded perlite modified with orthophenanthroline) were subjected to thermal study by TG/DTA using a simultaneous thermogravimetric analyzer SDTQ600 - TA Instruments. The purge gas was a nitrogen flow of $100 \mathrm{~mL} \cdot \mathrm{min}^{-1}$. A heating rate of $20^{\circ} \mathrm{Cmin}^{-1}$ was adopted, with samples weighing about $7-8 \mathrm{mg}$ and latinum crucible were used for TG - DTA.

\subsubsection{Molecular absorption spectroscopy in the infrared with Fourier transform (FTIR)}

Infrared spectra for samples were run on FTIR-8400S Iraffinity spectrometer, within the $4000-400 \mathrm{~cm}^{-1}$ range. The solid samples were pressed into $\mathrm{KBr}$ pellets.

\subsubsection{X-Ray Diffraction (XRD)}

X-ray powder patterns of the samples were obtained with a Bruker D2 Phaser ray diffractometer using Cu K $\alpha$ radiation $(\lambda=1.54 \AA)$, the filter of $\mathrm{Ni}$, settings of $30 \mathrm{kV}$ and $20 \mathrm{~mA}$.

\section{RESULTS AND DISCUSSION}

\subsection{Thermal analysis (TG/DTA)}

A study of the thermal stability of materials (expanded perlite, orthophenanthroline and expanded perlite modified orthophenanthroline) used in this study was submitted.

Figure 1 shows the TG/DTA curve of expanded perlite without modification. The TG curve of expanded perlite (Figure 1) shows only a small mass loss equal to $2,3 \%$, which takes place slowly, the initial temperature up to 432,9 ${ }^{\circ} \mathrm{C}$. After this temperature is observed a level of thermal stability of expanded perlite to final analysis temperature $\left(1000^{\circ} \mathrm{C}\right)$. The DTA curve shows an exothermic event indicative that there is a thermal decomposition of the material. Therefore, it is stated that the expanded perlite consists of a very stable material thermally attributed to its main establishment, $\mathrm{SiO}_{2}$ and $\mathrm{Al}_{2} \mathrm{O}_{3}$, representing its class, the aluminosilicate.

The orthophenanthroline was also subjected to thermal analysis, as shown in Figure 2. As seen by TG/DTA curve in this sample were observed two significant thermal events. The first mass loss that occurs from the initial heating temperature to $110,0{ }^{\circ} \mathrm{C}$ and this event represented by the presence of an endothermic peak in DTA curve is due to the dehydration of compound. The second thermal event, which begins shortly after the first, indicates a breakdown of orthophenanthroline, which is completely up to $296,7^{\circ} \mathrm{C}$, without final residue formation.

The study of thermal stability of the postchange material with orthophenanthroline was also made. Figure 3 shows the TG/DTA curve of expanded perlite modified orthophenanthroline. 
For the expanded perlite modified with orthophenanthroline, there was a lower thermal stability of the material mass loss and endothermic events characteristic of the presence of orthophenanthroline, with a total mass loss of $13,6 \%$, that is, by changing the thermal stability of the material modified, it is noted that there was the incorporation of the expanded perlite orthophenanthroline, since pure expanded perlite has only a small weight loss of $2,3 \%$ and the presence of peaks endothermic relating to thermal decomposition of orthophenanthroline (Figure 2). Thus, there is an embodiment of orthophenanthroline on the expanded perlite of $11,3 \%$ and an initial weight loss of up to approximately $100,3^{\circ} \mathrm{C}$ indicative of the dehydration step of the modifying agent, equivalent to $1,3 \%$ mass lost. In the thermal analysis of this modified material, it is also possible to note a third mass loss, which is absent in the expanded perlite without modification orthophenanthroline, with a slow and short thermal decomposition event.

In the case of the analysis of the thermal stability of the materials, it was observed that the orthophenanthroline decomposes completely at the studied temperatures and expanded perlite without modification has a relative thermal stability in the temperature range examined, with a miniature mass loss $(2,3 \%)$ plausible because the perlite it is an aluminosilicate comprised mainly of $\mathrm{SiO}_{2}$, a rather stable oxide thermally.

In the case of modified perlite, it was concluded that there was an interaction of orthophenanthroline on the surface perlite, since all orthophenanthroline impregnated in the material decomposes in the temperature range studied, and thus it is suggested that the molecules do not orthophenanthroline stepped into structure Inner expanded perlite (due to the expanded perlite not have lamellar structure), it would be more tightly bound to the material, since there remains a decrease in thermal stability of the perlite, with a more significant weight loss $(13,6 \%)$ and the DTA curve (Figure 3 ) the modified material is observed endothermic peaks relating to thermal decomposition of orthophenanthroline and there was an 11,3\% incorporation of the expanded perlite orthophenanthroline.

\subsection{X-Ray Diffraction (XRD)}

Materials used in this study were subjected to diffraction analysis of X-Rays is one of the main techniques for microstructural characterization of materials. In the diffractogram of orthophenanthroline (Figure 4) shows the presence of reflections in the range $10^{\circ}$ to $30^{\circ}$ in $2 \theta$, that have greater intensity reflections at $10^{\circ}$, $20^{\circ}$ and $30^{\circ}$ in $2 \theta$.

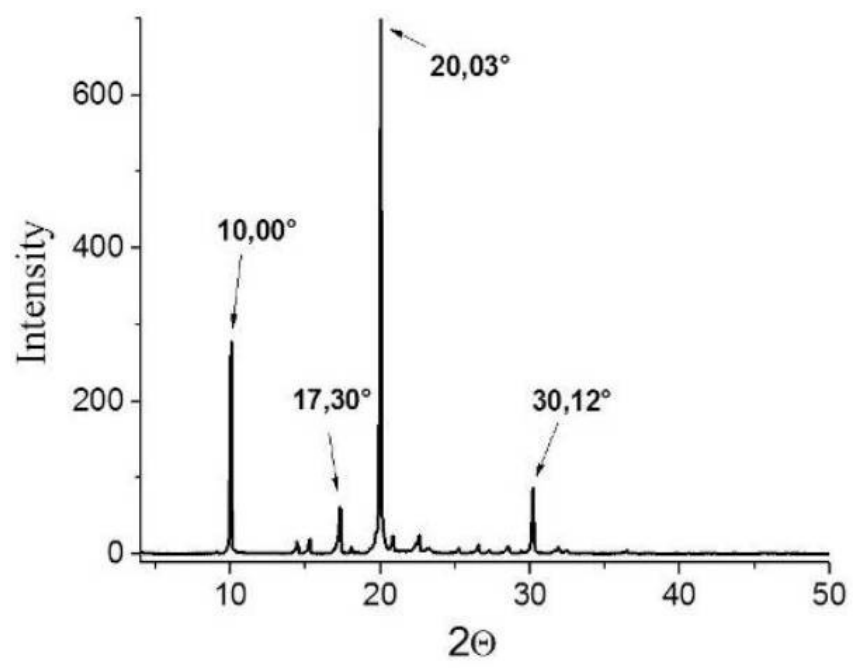

Figure 4. Diffractogram of orthophenanthroline

The diffractogram of expanded perlite (Figure 5 (a)) shows a broad reflection band in a range of $15^{\circ}$ to $35^{\circ}$ in $2 \theta$, characterized expanded perlite as a non-crystalline, it is classified as an amorphous aluminosilicate (DOGAN e ALKAN, 2004).

Unexpanded perlite has an amorphous nature but shows a trace mineral: feldspar, biotite and quartz. And that the presence and quantity of these minerals in perlite depend on the origin of perlite and lava that gave rise to cooling rate if the presence of these minerals are favored starting from a slow cooling of magma, which gives rise to rock. But and the expanded perlite is clearly amorphous (ROULIA et al, 2006), as can be seen in XRD obtained from this study.

For the expanded perlite modified with orthophenanthroline, the XRD (Figure 5 (b)) showed some reflections concerning orthophenanthroline $\left(10^{\circ}\right.$ and $20^{\circ}$ in $\left.2 \theta\right)$, and a very intense reflection at $2 \theta$ of $17.30^{\circ}$ as well visualized the XRD of orthophenanthroline. This 
indicates that there was the incorporation of orthophenanthroline in the expanded perlite.

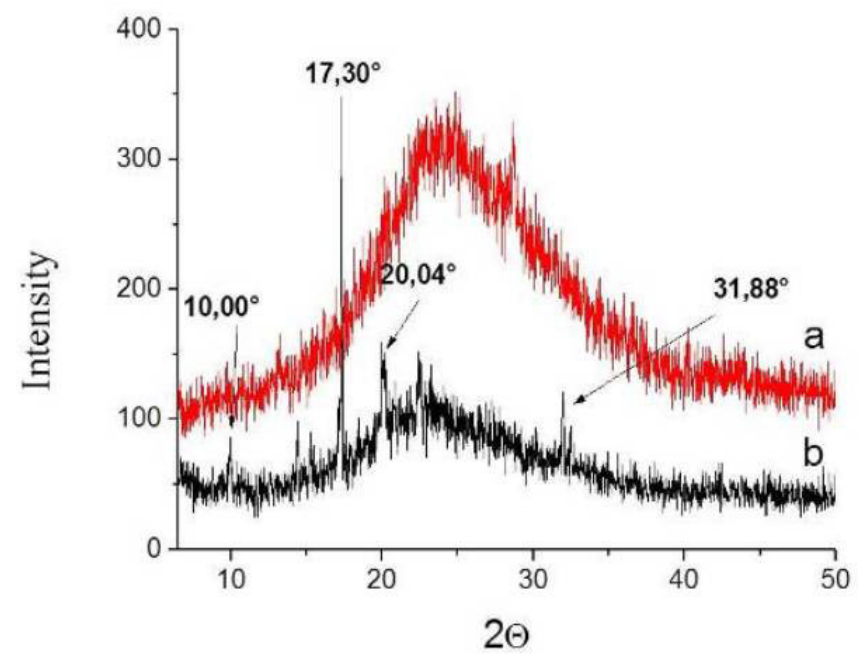

Figure 5. Diffractogram of expanded perlite (a) and expanded perlite modified orthophenanthroline (b)

\subsection{Infrared Spectroscopy (FTIR)}

The expanded perlite infrared spectrum as shown in Figure 6, presenting a strong band in the region $1053 \mathrm{~cm}^{-1}$ relating to vibration of the $\mathrm{Si}-\mathrm{O}$ bond, which is expected since the main constituent of the expanded perlite is silicon oxide $\left(\mathrm{SiO}_{2}\right)$. The broadband $3459 \mathrm{~cm}^{-1}$ is indicative of the axial deformation of $\mathrm{OH}$ of $\mathrm{Si}-\mathrm{OH}$ groups of perlite. At $782 \mathrm{~cm}^{-1}$ have the deformation of Al-O$\mathrm{Si}$ groups also present in the constitution of expanded perlite as an aluminosilicate (SILVERSTEIN, WEBSTER e KIEMLE, 2006).

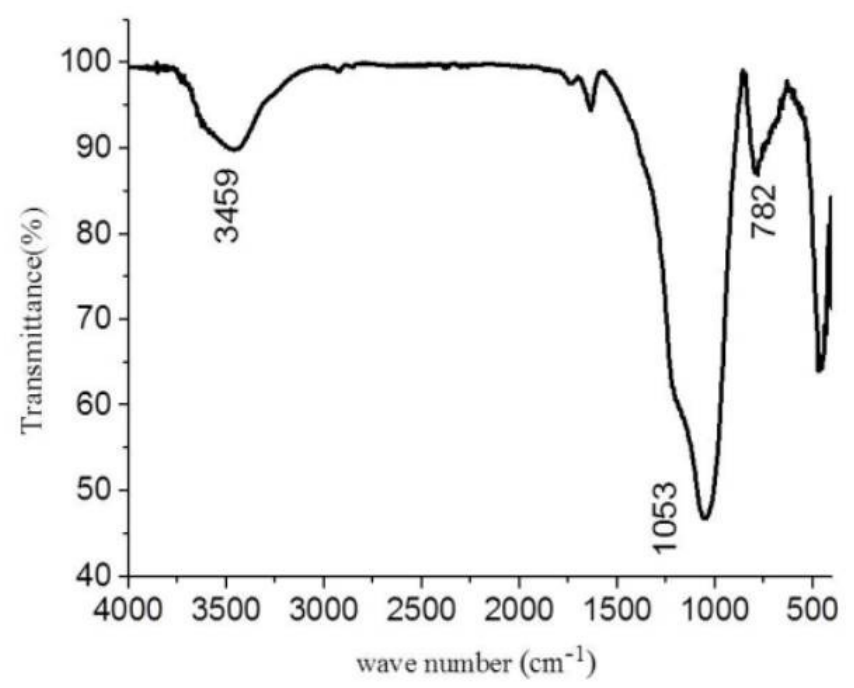

Figure 6. The expanded perlite infrared spectrum
The infrared absorption spectrum of orthophenanthroline (Figure 7) shows the welldefined band at $3375 \mathrm{~cm}^{-1}$ characteristics of secondary amines. Bands corresponding to the axial deformation of the aromatic $\mathrm{C}-\mathrm{H}$ bond occurred at $3066 \mathrm{~cm}^{-1}$. In the spectral range 1502 - $1423 \mathrm{~cm}^{-1}$ refer to two bands and a weak another medium intensity attributed to stretching vibrational modes $\mathrm{C}=\mathrm{C}, \mathrm{C}-\mathrm{N}$ aromatic ring. The bands observed at $849 \mathrm{~cm}^{-1}$ and $734 \mathrm{~cm}^{-1}$ refer to angular deformation out of the plane of the ring for $\mathrm{C}-\mathrm{H}$ bonds. These bands observed are provided according to the chemical structure of orthophenanthroline.

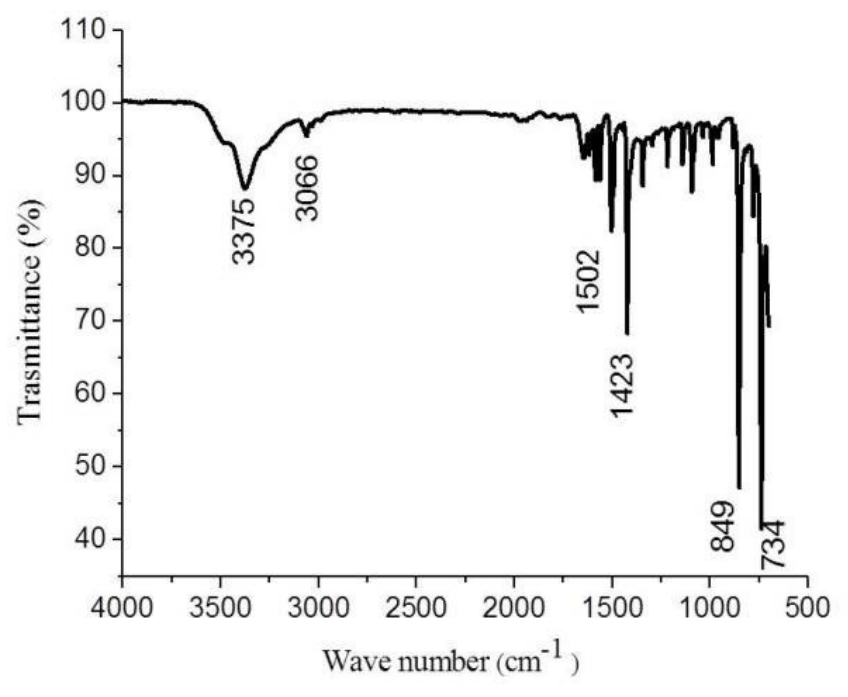

Figure 7. The infrared absorption spectrum of orthophenanthroline

In the infrared spectrum adsorbent modified with orthophenanthroline (Figure 8), it was observed that the absorption band at 1053 $\mathrm{cm}^{-1}$ which is related to vibration of the $\mathrm{Si}-\mathrm{O}$ bond of the groups present in the unmodified expanded perlite is shifted lower wavenumber, in this case, the band appears in modified material $1047 \mathrm{~cm}^{-1}$ absorption spectrum. The increase of intensity and enlargement of the band in the IR important and characteristic of expanded perlite consists of an indication of the presence of orthophenanthroline cause effects on the active sites of the material (silanol groups). 


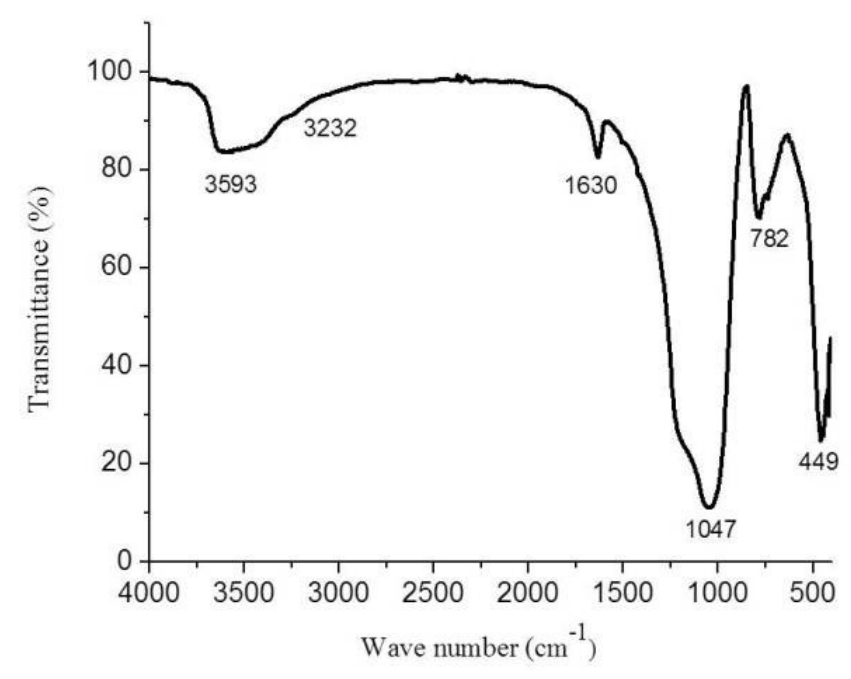

Figure 8. Infrared spectrum adsorbent modified with orthophenanthroline

However, the absorption band of the expanded perlite, related to the axial deformation of $\mathrm{OH} \mathrm{Si-OH}$ groups (silanol groups), appear in the infrared spectrum of the modified material in the form of a tape somewhat wider and more intense. Probably there was an overlap of bands related to the axial deformation of the $\mathrm{OH}$ group and the absorption band related secondary amines which occur almost in the same spectral region $3459-3375 \mathrm{~cm}^{-1}$, respectively.

In some system that containing proton donor group and group that is an acceptor of protons may be hydrogen bond. A common proton-donating group is hydroxy and acceptor is nitrogen and unsaturated groups such as $\mathrm{C}=\mathrm{C}$ bonds can also act as proton acceptors (SILVERSTEIN, WEBSTER e KIEMLE, 2006). The occurrence of hydrogen bond can extend and intensify the band in the absorption spectrum.

Therefore it can suggest that an interaction occurred between the $\mathrm{OH}$ groups of the silanol groups of perlite with the unshared electron pairs of the nitrogen atoms and $\mathrm{C}=\mathrm{C}$ bonds (also rich in electrons) present in chemical structure as a consequence of a hydrogen bond between these groups.

Knowing that the silanol groups are highly sensitive to the presence of other organic molecules able to interact with the same, these are the groups present on the surface of expanded perlite which has attracted to organic molecules, which are adsorbed on the surface than of the perlite expanded.
This interaction of the silanol groups organic molecules are due to the occurrence of an interaction by hydrogen bond of the $\mathrm{OH}$ groups (silanols groups) of the perlite with unshared pairs of electrons and $\pi$ electrons of $\mathrm{C}=\mathrm{C}$ bonds present in the aromatic structure the orthophenanthroline. In view of this, it can be stated that the process of interaction between the surface of the expanded perlite with orthophenanthroline characterized by being a surface reaction, it can be said, by an adsorption of orthophenanthroline on the surface of perlite, thus no changes in the internal structure of the adsorbent, only a process of organofunctionalization by adsorption or interaction, by only changing surface characteristics of material ${ }^{11}$.

\section{CONCLUSIONS}

According to the data already shown in the characterization section of the materials used in this study, it was observed as results of the techniques of X-Ray Diffraction, Thermogravimetry/ Differential Thermal Analysis and Infrared Spectroscopy that there was a change of structural, thermal and chemical properties the material, in this case, the expanded perlite modified orthophenanthroline.

In the case of the analysis of the thermal stability of the materials, it was observed that the orthophenanthroline decomposes completely at the studied temperatures and without modification expanded perlite has a relative thermal stability in the temperature range examined, with a small weight loss $(2,3 \%)$ if plausible because the perlite it is an aluminosilicate comprised mainly of $\mathrm{SiO}_{2}$ a rather stable oxide termally. In the case of modified perlite, it was concluded that there was an interaction of orthophenanthroline on the surface perlite, since all orthophenanthroline impregnated in the material decomposes in the temperature range studied, and thus it is suggested that the molecules do not orthophenanthroline stepped into structure Inner expanded perlite, because it would be more tightly bound to the material, since there is a decrease in thermal stability of the perlite, with a more significant weight loss $(13,60 \%)$ and the DTA curve (Figure 3) material modified observed endothermic peaks relating to thermal decomposition of orthophenanthroline and that there was an incorporation of $11.3 \%$ of orthophenanthroline the expanded perlite. 
By the XRD analysis (Figure 4 and 5 ) is visualized and the presence of reflections in the diffractogram relating to the modified material of orthophenanthroline peaks of crystallinity, since the expanded perlite without modification, behaves as an amorphous material.

In the infrared modified by perlite characterization technique, we observed an increase in intensity and a detailed enlargement of the absorption band related to the axial deformation of the $\mathrm{OH}$ bond of silanol groups of perlite $(\mathrm{Si}-\mathrm{OH})$.

Thus, orthophenanthroline effectively interacted with the acid sites of expanded perlite producing a new material capable of receiving molecules with acidic groups, as some dyes in adsorption processes.

\section{ACKNOWLEDGEMENTS}

CAPES, FAPERN, LAQUAM/ UFRN, LABPMOL UFRN, ANALYTICAL CENTER/ UFRN.

\section{REFERENCES}

1. Chassapis, K., Roulia, M., Vrettou, E., Parassiris, A. Colloids Surf., B, 2010, 81, 115.

2. Dogan, M., Alkan, M., Onganer, Y. Water, Air, Soil Pollut., ,-2000, 120, 229.

3. Alkan, M., Dogan, M. 'Journal of Colloid Interface Sci.,_1998, 207, 90.

4. Silber, A.; Bar-Yosef, B.; Levkovich, I.; Soryano, S. Geoderma, 2010, 158.

5. Dogan, M.; Alkan, M.; Çakir, U. Journal of Colloid and Interface Science, 1997, 192.

6. Barka, N.; Abdennouri, M.; El Makhfouk, $\mathrm{M}$. Journal of the Taiwan Institute of Chemical Engineers, 2011, 42.

7. Aguiar, M. R. M. P; Novaes, A. C.; Guarino, A. W. S. Química Nova, 2002, 25, 6.

8. Varlikli, C. Journal of Hazardous Materials, 2009, 170.

9. Dotto, G. L.; Vieira, M. L. G.; Gonçalves, J. O.; Pinto, L. A. A.; Química Nova, 2011, $34,7$.

10. Hernandéz-Montoya, A. Journal of Evironmental Management, 2013, 116.

11. Acemioglu, B. Chem. Eng. J., 2005, 106, 73.

12. Roulia, M., Vassiliadis, A. A. J. Colloid Interface Sci., 2005, 18, 37.
13. Ghassabzadeh, H., Mohadespous, A., Torab-Morastaedi, M., Zaheri, P., Maragheh, M. G., Taheri, H. J. Hazard. Mater., 2010, 177, 950.

14. Roulia, M., Chassapis, K., Kapoutsis, J. A., Kamitsos, E. I., Savvidis, T. J. Mater. Sci., 2006, 41, 5870.

15. Sari, A., Sahinoglu, G., Tuzen, M. Ind. Eng. Chem. Res., 2012, 51, 6877.

16. Dogan, M., Alkan, M., Türkylmaz, A. Özdemir, Y. J. Hazard. Mater., 2004, 109, 141.

17. Silverstein, R. M., Webster, F. X., Kiemle, D. J. 7nd edn, Vol. 1,490 p, 2006.

18. Bergaya, F., Lagaly, G. Appl. Clay Sci., 2001, 19, 1.

19. Tekin, N., Kadinci, E., Demirbas, O., Alkan, M., Kara, A., Dogan, M. Microporous Materials, 2006, 93,125-133.

20. Atkinson, P.W., Fuller, R.J., Vickery, J.A., Conway, G.J., Tallowins, J.R., Smith, R.E., Hayson, K.A., Ings, T.C., Brown, V.K. J. Appl. Ecol, 2005, 42, 932. . 


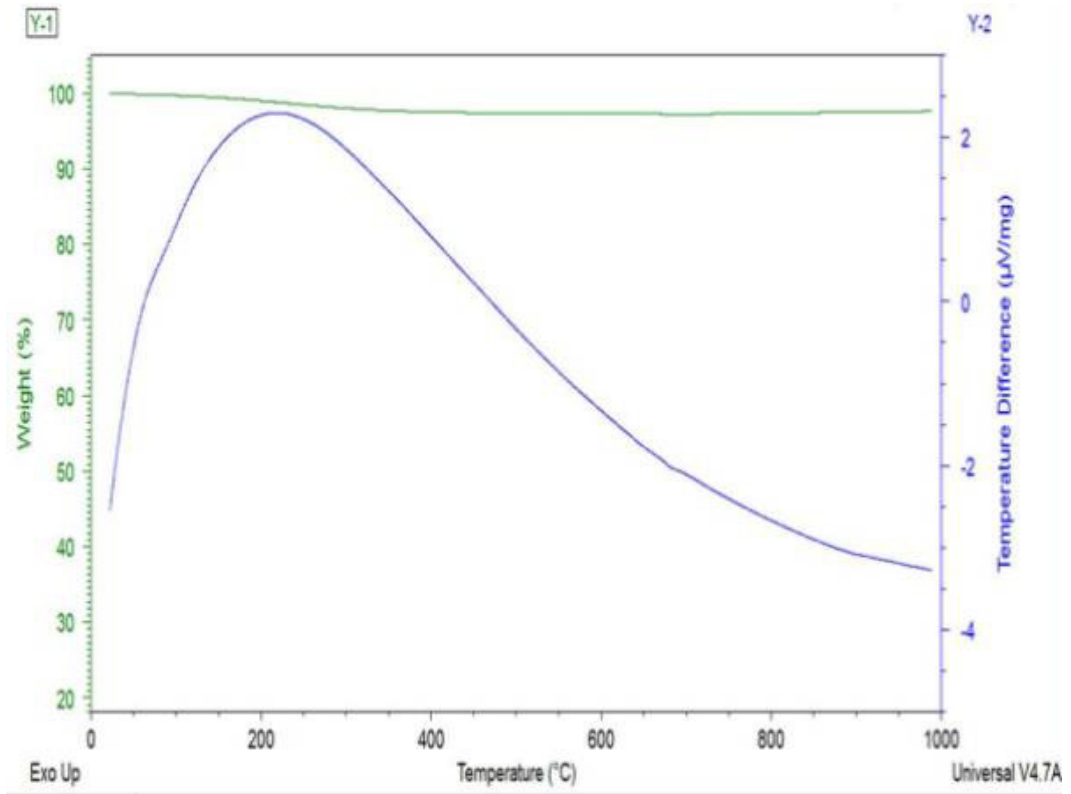

Figure 1. TA curve of expanded perlite

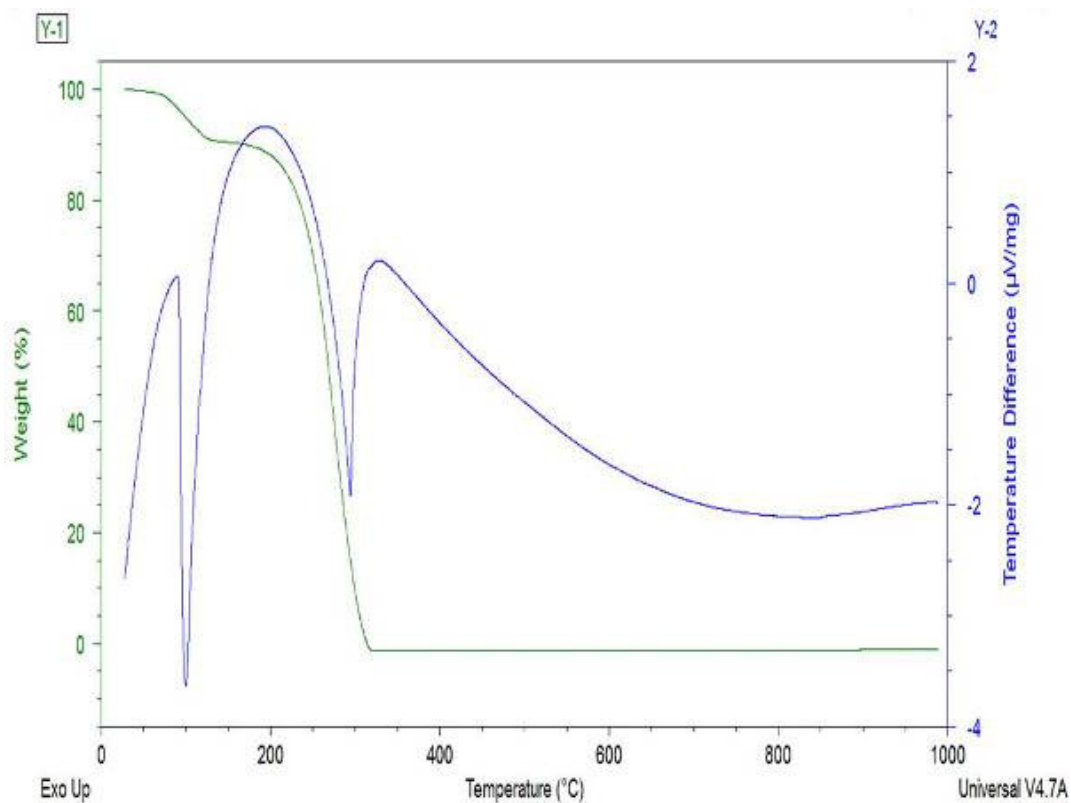

Figure 2. TG/DTA curve orthophenanthroline 


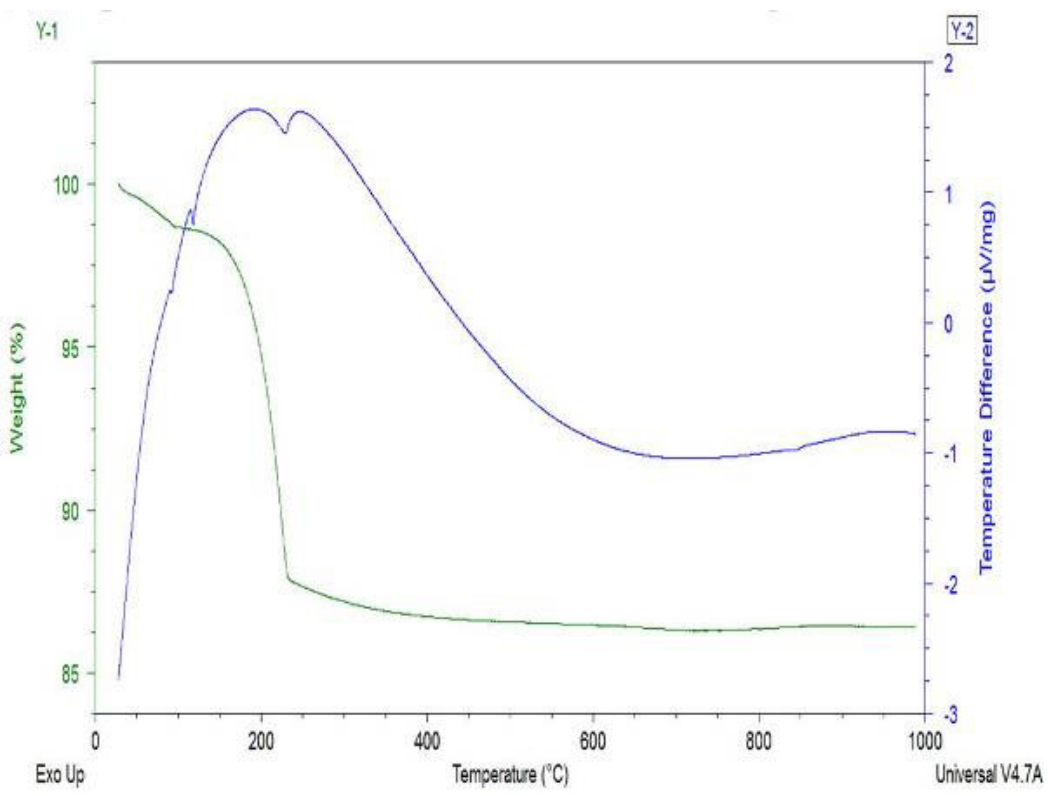

Figure 3. TA/DTA curve of expanded perlite modified with orthophenanthroline

PERIÓDICO TCHÊ QUÍMICA • www.periodico.tchequimica.com • Vol. 15 N. 30.

• ISSN 1806-0374 (impresso) • ISSN 1806-9827 (CD-ROM) • ISSN 2179-0302 (meio eletrônico)

(C) 2018. Porto Alegre, RS. Brasil

The Periódico Tchê Química (ISSN: 1806-0374; 2179-0302) is an open-access journal since 2004. Journal DOI: 10.52571/PTQ. http://www.tchequimica.com. This text was introduced in this file in 2021 for compliance reasons.

(c) The Author(s)

OPEN ACCESS. This article is licensed under a Creative Commons Attribution 4.0 (CC BY 4.0) International License, which permits use, sharing, adaptation, distribution, and reproduction in any medium or format, as long as you give appropriate credit to the original author(s) and the source, provide a link to the Creative Commons license, and indicate if changes were made. The images or other third-party material in this article are included in the article 's Creative Commons license unless indicated otherwise in a credit line to the material. If material is not included in the article's Creative Commons license and your intended use is not permitted by statutory regulation or exceeds the permitted use, you will need to obtain permission directly from the copyright holder. To view a copy of this license, visit http://creativecommons.org/licenses/by/4.0/. 